\title{
Hemoglobin levels during the first trimester of pregnancy are associated with the risk of gestational diabetes mellitus, pre-eclampsia and preterm birth in Chinese women: a retrospective study
}

Chen Wang ${ }^{1}$, Li Lin ${ }^{1}$, Rina Su', Weiwei Zhu ${ }^{1,2}$, Yumei Wei ${ }^{1}$, Jie Yan ${ }^{1}$, Hui Feng ${ }^{1}$, Boya Li ${ }^{1}$, Shuang Li ${ }^{1}$ and Huixia Yang ${ }^{1 *}$ (D)

\begin{abstract}
Background: Hemoglobin $(\mathrm{Hb})$ measurement is a standard test among pregnant women during the first perinatal visit that is used to evaluate physical status and anemia. However, studies focusing on Hb levels and pregnancy outcomes are scarce. This study aimed to determine whether Hb levels in early pregnancy were associated with the risk of gestational diabetes mellitus (GDM), pre-eclampsia (PE) and preterm birth.

Methods: A hospital-based retrospective study was conducted among 21,577 singleton, non-smoking pregnancies between June 2013 and January 2015. The demographic data and medical information of each participant were collected individually through questionnaires and patient medical records. Odds ratios were generated using a multivariate logistic regression analysis to evaluate the relative risk of GDM, PE and preterm birth continuously and across different hemoglobin ranges in the overall population and in women from different pre-pregnancy body mass index (BMI) categories, respectively. The level of statistical significance was set at 0.05 .
\end{abstract}

Results: (1) For women who were underweight, normal-weight, overweight and obese, early pregnancy Hb levels were $127.8 \pm 10.1 \mathrm{~g} / \mathrm{L}, 129.6 \pm 9.7 \mathrm{~g} / \mathrm{L}, 132.2 \pm 9.5 \mathrm{~g} / \mathrm{L}$ and $133.4 \pm 9.4 \mathrm{~g} / \mathrm{L}$, respectively. (2) Women with GDM and PE had significantly increased $\mathrm{Hb}$ levels during early pregnancy compared with controls, whereas women with preterm birth processed significantly decreased $\mathrm{Hb}$ levels. (3) After adjusting for confounders, the risks for GDM and PE increased with high maternal Hb (OR: 1.27 for Hb 130-149; OR: 2.06 for $\mathrm{Hb} \geq 150 \mathrm{~g} / \mathrm{L}$ ), and the risk for preterm birth decreased with high maternal $\mathrm{Hb}$ (OR: 1.30 for $\mathrm{Hb}$ 130-149; OR: 2.38 for $\mathrm{Hb} \geq 150 \mathrm{~g} / \mathrm{L}$ ) and increased with low maternal $\mathrm{Hb}$ (OR: 1.41 for $\mathrm{Hb}<110 \mathrm{~g} / \mathrm{L}$ ). Among women whose BMl was $<24 \mathrm{~kg} / \mathrm{m}^{2}$, high GDM (OR: 1.27 for $\mathrm{Hb}$ 130-149; OR: 1.84 for $\mathrm{Hb} \geq 150 \mathrm{~g} / \mathrm{L}$ ) and low preterm rates (OR: 0.77 for Hb 130-149; OR: 0.23 for $\mathrm{Hb} \geq 150 \mathrm{~g} / \mathrm{L}$ ) were observed with high $\mathrm{Hb}$, whereas in women whose BMI was $\geq 24 \mathrm{~kg} / \mathrm{m}^{2}$, only high GDM rates were observed with $\mathrm{Hb}>150 \mathrm{~g} / \mathrm{L}$ (OR: 2.33).

Conclusion: These findings suggest that Hb levels during early pregnancy play a role in predicting the risk of GDM, PE and preterm birth.

Keywords: Hemoglobin, Gestational diabetes mellitus, Pre-eclampsia, Preterm birth, Body mass index

\footnotetext{
* Correspondence: yanghuixia@bjmu.edu.cn

'Department of Obstetrics and Gynecology of Peking University First

Hospital, Xianmen Street No. 1, Xicheng District, Beijing 100034, China

Full list of author information is available at the end of the article
}

(c) The Author(s). 2018 Open Access This article is distributed under the terms of the Creative Commons Attribution 4.0 International License (http://creativecommons.org/licenses/by/4.0/), which permits unrestricted use, distribution, and reproduction in any medium, provided you give appropriate credit to the original author(s) and the source, provide a link to the Creative Commons license, and indicate if changes were made. The Creative Commons Public Domain Dedication waiver (http://creativecommons.org/publicdomain/zero/1.0/) applies to the data made available in this article, unless otherwise stated. 


\section{Background}

Gestational diabetes mellitus (GDM) and pre-eclampsia (PE) are two of the most common complications during pregnancy. Both GDM and PE contribute significantly to maternal, fetal and neonatal morbidity and mortality. Furthermore, they may result in adverse consequences for the health of both the mother and offspring later in life [1-3]. Previous epidemiological studies have shown that GDM and PE occur in 9.3\%-25.5\% [4] and 0.2-9.2\% [3] of pregnancies, respectively, in different global populations. Additionally, preterm birth, which accounts for $11.1 \%$ of live births worldwide, is also an important concern during pregnancy [5]. Preterm birth is a major determinant of neonatal death or child loss. Furthermore, children who are born prematurely have a higher risk of cerebral palsy, cardiovascular disease, pulmonary illnesses or psychological diseases, and these conditions can persist throughout life [6]. Thus, predicting GDM, $\mathrm{PE}$, and preterm birth is essential and imperative for improving the health quality of populations.

Hemoglobin $(\mathrm{Hb})$ measurement is a standard test among pregnant women during the first perinatal visit that is used to evaluate physical status and anemia. According to the World Health Organization [7], anemia is diagnosed when a blood test shows an $\mathrm{Hb}$ value of less than $110 \mathrm{~g} / \mathrm{L}$ in pregnant women. Observational studies have found that anemia during pregnancy is associated with detrimental pregnancy outcomes, including preterm birth, low birth weight, infection and hemorrhage [8]. Additionally, several studies have even reported that high $\mathrm{Hb}$ levels during pregnancy could also be a predictor or cause of some pregnancy complications [9-11]. However, studies focusing on $\mathrm{Hb}$ levels and pregnancy outcomes are scarce, and the findings are inconsistent due to a wide variation in study designs, sample sizes, populations and the time of $\mathrm{Hb}$ testing. Moreover, high maternal $\mathrm{Hb}$ has not received the same attention as anemia because it is more likely to be perceived as a symbol of good nutrition status. Furthermore, previous studies indicated that $\mathrm{Hb}$ levels during pregnancy were significantly associated with body mass index (BMI) [12]. However, few studies to date have assessed the effects of maternal Hb values in the first trimester stratified by pre-pregnancy BMI on pregnancy complications. Thus, in this large sample study, we aimed to conduct stratified analyses modified by pre-pregnancy BMI and to evaluate whether associations exist between $\mathrm{Hb}$ levels in the first trimester and the risk of GDM, PE, and preterm birth.

\section{Methods}

\section{Study design and participants}

Data for this current analysis was obtained from a hospital-based retrospective study of 44,002 pregnant women who gave birth between June 2013 and January 2015 at 21 hospitals throughout three cities in China. One of the three cities was Beijing, the capital city of China, which is located in northern China. The two other cities were Guangzhou and Chengdu, which are the provincial capital cities of Guangdong and Sichuan provinces, located in southern and western China, respectively. Participants in our study were stratified according to their $\mathrm{Hb}$ levels in the first trimester combined with their pre-pregnancy BMI. These values were compared to the incidence rates of GDM, PE, and preterm delivery. The study was reviewed and approved by the Institutional Review Board of the First Hospital, Peking University (Reference number: 2013[578]). All participants provided written informed consent, and the Ethics Committee approved this consent procedure.

All participants in the retrospective study were eligible for the present analysis if they were singleton, non-smoking pregnant women with their $\mathrm{Hb}$ measured at $<14$ weeks of gestation and had complete maternal and infant records. However, if the participants in our study were reported a diagnosis of diabetes, chronic hypertension, cardiovascular disease, thyroid disorder, respiratory ailments, placenta previa, fetal anomalies or histories of poor pregnancy outcomes, they would be excluded. Overall, a total of 21,577 participants were available for and included in the final analysis.

\section{Data collection}

The demographic and medical information for each participant were collected by using a structured questionnaire the day after they gave birth. Demographic information, such as maternal age, pre-pregnancy weight, height, educational level and family financial status were collected from all participants via in-person interviews. Medical data such as medical history, previous obstetric history, laboratory parameters such as $\mathrm{Hb}$ and glucose values, diagnosis of GDM and PE, and gestational weeks at delivery were extracted from the medical records.

All the investigators at each hospital received standard training before administering the survey. Each completed questionnaire was reviewed by an inspector. Data were coded and entered into a specially designed data software program that automatically flagged out-ofrange values and logical errors. All questionnaires were entered independently by two individuals and were then verified by a third person.

Definitions:

(1) BMI categories: Pre-pregnancy BMI was calculated as the body weight within the 3 months prior to pregnancy in kilograms divided by height in meters squared $\left(\mathrm{kg} / \mathrm{m}^{2}\right)$. Based on the criteria recommended by the China Obesity Task Force of the Chinese 
Ministry of Health [13], the participants were categorized as follows: underweight: $\mathrm{BMI}<18.5 \mathrm{~kg} / \mathrm{m}^{2}$; normal weight: $18.5 \leq \mathrm{BMI}<24 \mathrm{~kg} / \mathrm{m}^{2}$; overweight: $24 \leq \mathrm{BMI}<28 \mathrm{~kg} / \mathrm{m}^{2}$; and obese: BMI $\geq 28 \mathrm{~kg} / \mathrm{m}^{2}$. In this study, we categorized participants into two groups: pre-pregnancy BMI $<24 \mathrm{~kg} / \mathrm{m}^{2}$ and pre-pregnancy $\mathrm{BMI} \geq 24 \mathrm{~kg} / \mathrm{m}^{2}$.

(2) Hb groups: According to the median $\mathrm{Hb}$ level in our study $(130 \mathrm{~g} / \mathrm{L})$ and the definition of anemia during pregnancy $(\mathrm{Hb}<110 \mathrm{~g} / \mathrm{L})$, we divided the participants into 4 groups: Group 1: $\mathrm{Hb}<110 \mathrm{~g} / \mathrm{L}$ (anemia group); Group 2: $110 \mathrm{~g} / \mathrm{L} \leq \mathrm{Hb}<130 \mathrm{~g} / \mathrm{L}$ (reference group); Group 3: $130 \mathrm{~g} / \mathrm{L} \leq \mathrm{Hb}<150 \mathrm{~g} / \mathrm{L}$; and Group 4: $\mathrm{Hb} \geq 150 \mathrm{~g} / \mathrm{L}$.

(3) GDM: The GDM diagnostic criteria followed the newly amended China's Ministry of Health criteria, which were published in August 2014. These criteria recommended that the diagnosis of GDM should be made when any one 75-g oral glucose tolerance test (OGTT) value met or exceeded $5.1 \mathrm{mmol} / \mathrm{L}$ at $0 \mathrm{~h}, 10.0 \mathrm{mmol} / \mathrm{L}$ at $1 \mathrm{~h}$, or $8.5 \mathrm{mmol} / \mathrm{L}$ at $2 \mathrm{~h}$ when performed between 24 and 28 gestational weeks. Furthermore, an OGTT result of $7.0 \mathrm{mmol} / \mathrm{L}$ at $0 \mathrm{~h}$ or $11.1 \mathrm{mmol} / \mathrm{L}$ at $2 \mathrm{~h}$ should be diagnosed with diabetes at any time [14].

(4) PE: PE was defined as new-onset hypertension (systolic blood pressure of $\geq 140 \mathrm{mmHg}$ and/or diastolic blood pressure $\geq 90 \mathrm{mmHg}$ ) with new-onset proteinuria (300 $\mathrm{mg}$ of protein/day or a urine protein/creatinine ratio of $0.3 \mathrm{mg} / \mathrm{dL}$ ) after 20 weeks of gestation in a previously normotensive woman [3].
(5) Preterm birth: Preterm birth was defined according to the World Health Organization's criteria as all births before 37 completed weeks or before 259 completed days since the first day of a woman's last menstrual period [15].

\section{Statistical analyses}

All statistical analyses were performed using the SAS 9.2 statistical software package (Peking University Clinical Research Institute). Figure 4 was created using Stata 9.0 (Peking University Clinical Research Institute). Continuous variables were expressed as the means \pm standard deviations, and categorical variables were expressed numerically and as percentages. Differences in the means between groups were assessed using the independent samples t-test and analysis of variance (ANOVA), whereas the Pearson's chi-square test or Fisher's exact test (if the variable contained fewer than five measurements) was used for categorical variables. A multivariate binary logistic regression analysis was conducted to evaluate the relative risk by generating the odds ratios (ORs) and 95\% confidence intervals (CIs) for GDM, PE, and preterm birth continuously and across different $\mathrm{Hb}$ ranges for the overall population and for women with different pre-pregnancy BMI categories. Additionally, Group $2(110 \mathrm{~g} / \mathrm{L} \leq \mathrm{Hb}<130 \mathrm{~g} / \mathrm{L})$ was defined as the reference group. Models were adjusted for maternal age, pre-pregnancy BMI, gravidity $(<2, \geq 2)$, parity (yes, no), education level $(\leq 12,>12)$, and gestational age at the time of $\mathrm{Hb}$ measurement to estimate the ORs for the associations between $\mathrm{PE}$ and $\mathrm{Hb}$ levels in the first trimester. For the GDM analyses, we further included a

Table 1 Baseline characteristics of the total sample population and subgroups stratified by hemoglobin ranges

\begin{tabular}{|c|c|c|c|c|c|c|}
\hline & $\begin{array}{l}\text { Total } \\
n=21,577\end{array}$ & $\begin{array}{l}\mathrm{Hb}<110 \mathrm{~g} / \mathrm{L} \\
n=584\end{array}$ & $\begin{array}{l}110 \mathrm{~g} / \mathrm{L} \leq \mathrm{Hb}<130 \mathrm{~g} / \mathrm{L} \\
n=9397\end{array}$ & $\begin{array}{l}130 \mathrm{~g} / \mathrm{L} \leq \mathrm{Hb}<150 \mathrm{~g} / \mathrm{L} \\
n=11,268\end{array}$ & $\begin{array}{l}\mathrm{Hb} \geq 150 \mathrm{~g} / \mathrm{L} \\
n=328\end{array}$ & $p$-value \\
\hline Age (years) & $29.8 \pm 3.9$ & $29.6 \pm 4.3$ & $29.7 \pm 4.0$ & $29.9 \pm 3.7$ & $30.1 \pm 4.3$ & 0.005 \\
\hline Pre-pregnancy BMI $\left(\mathrm{kg} / \mathrm{m}^{2}\right)$ & $21.4 \pm 3.3$ & $20.5 \pm 4.8$ & $21.0 \pm 3.1$ & $21.8 \pm 3.4$ & $22.8 \pm 4.3$ & $<0.001$ \\
\hline Overweight/Obesity & $3783(17.5)$ & $56(9.6)$ & $1232(13.1)$ & $2392(21.2)$ & $103(31.4)$ & $<0.001$ \\
\hline Underweight & $3330(14.4)$ & $129(22.1)$ & $1720(18.3)$ & $1452(12.9)$ & $29(8.8)$ & $<0.001$ \\
\hline Education level (school years) $>12$ & $17,358(80.4)$ & $399(68.3)$ & $7358(78.3)$ & $9341(82.9)$ & $260(79.4)$ & $<0.001$ \\
\hline Average monthly income & & & & & & $<0.001$ \\
\hline$\geq 5000$ & $8713(40.4)$ & $255(43.6)$ & $3787(40.3)$ & $4552(40.4)$ & $119(36.4)$ & \\
\hline 3000-4999 & $4287(19.9)$ & $155(26.5)$ & $1983(21.1)$ & $2085(18.5)$ & $64(19.4)$ & \\
\hline 1000-2999 & $3238(15.0)$ & $62(10.7)$ & $1278(13.6)$ & $1837(16.3)$ & $61(18.5)$ & \\
\hline$<1000$ & $5339(24.7)$ & $112(19.2)$ & $2349(25.0)$ & $2794(24.8)$ & $84(25.7)$ & \\
\hline Parity (nulliparous) & $12,409(57.5)$ & $215(36.9)$ & $4792(51.0)$ & 7166 (63.6) & $236(71.9)$ & $<0.001$ \\
\hline Family history of DM & $2376(11.0)$ & $27(4.9)$ & $818(8.7)$ & $1487(13.2)$ & $44(13.5)$ & $<0.001$ \\
\hline Hb levels ( $\mathrm{g} / \mathrm{L})$ & $129.9 \pm 9.8$ & $103.2 \pm 5.9$ & $122.8 \pm 4.9$ & $136.4 \pm 4.8$ & $153.9 \pm 5.2$ & $<0.001$ \\
\hline
\end{tabular}

Data are represented as the mean \pm SD or $n$ (\%). The $p$-values refer to the overall differences across the Hb groups as derived from ANOVA (for continuous variables) or $\mathrm{X}^{2}$ tests (for categorical variables)

Abbreviations: $\mathrm{Hb}$ hemoglobin, $\mathrm{BMI}$ body mass index 
family history of diabetes (yes, no) as a confounder, and for the preterm birth analyses, we included GDM and PE as confounders. Additionally, we used restricted cubic spline regressions to model the associations between continuous $\mathrm{Hb}$ levels and the risk of GDM, PE, and preterm birth for the entire population and for the different pre-pregnancy BMI subgroups.

\section{Results}

Among the 21,577 eligible women, the mean maternal $\mathrm{Hb}$ level in the first trimester was $129.9 \mathrm{~g} / \mathrm{L}$. Five hundred eighty-four women (2.7\%) had anemia during the first trimester. The baseline characteristics of the total sample population and subgroups stratified by $\mathrm{Hb}$ ranges are presented in Table 1 . On average, the mean maternal age was $29.8 \pm 3.9$ years old, $17.5 \%$ of the participants had a pre-pregnancy BMI of $24 \mathrm{~kg} / \mathrm{m}^{2}$ or higher, and most of them had a high education level. A total of $70.4 \%$ of the participants were nulliparous, and $11.0 \%$ reported a family history of diabetes. Compared with the total population, participants in our study were more likely to have a family history of diabetes $(11.0 \%$ vs. $9.0 \%, p<0.001)$. However, their age, pre-pregnancy $\mathrm{BMI}$, education levels, average monthly income and $\mathrm{Hb}$ levels in the first trimester were not significantly different.

Women who were classified as having the highest $\mathrm{Hb}$ level in the first trimester were more likely to be older, nulliparous, and have a higher pre-pregnancy BMI and family history of diabetes, whereas women in the lowest $\mathrm{Hb}$ level group had the opposite characteristics. For women who were underweight, normalweight, overweight and obese, early pregnancy $\mathrm{Hb}$ levels were $127.8 \pm 10.1 \mathrm{~g} / \mathrm{L}, 129.6 \pm 9.7 \mathrm{~g} / \mathrm{L}, 132.2 \pm 9.5 \mathrm{~g} / \mathrm{L}$ and $133.4 \pm 9.4 \mathrm{~g} / \mathrm{L}$, respectively. Furthermore, by dividing the studied population into two subgroups, namely, pre-pregnancy $\mathrm{BMI}<24 \mathrm{~kg} / \mathrm{m}^{2}$ and pre-pregnancy $\mathrm{BMI} \geq 24 \mathrm{~kg} / \mathrm{m}^{2}$, we found that pregnant women in the high BMI group had significantly higher levels of $\mathrm{Hb}$ during the first trimester (pre-pregnancy BMI $<24 \mathrm{~kg} / \mathrm{m}^{2}$ vs. pre-pregnancy BMI $\geq 24 \mathrm{~kg} / \mathrm{m}^{2}: 129.3 \pm 9.8 \mathrm{~g} / \mathrm{L}$ vs. 132 . $6 \pm 9.5 \mathrm{~g} / \mathrm{L} ; p<0.001$ ) (Fig. 1). The distribution of $\mathrm{Hb}$ levels in the first trimester according to BMI can be seen in Fig. 2.

Overall, there were 4337 cases and 284 cases diagnosed with GDM and PE, with an incidence of 20.1 and $1.3 \%$, respectively. There were 1027 preterm births, with an incidence of $4.8 \%$. Compared with the original sample, the incidence of GDM in our study was not significantly different $(20.1 \%$ vs. $19.7 \%, p=0.208)$, whereas the incidence of PE $(1.3 \%$ vs. $2.2 \%, p<0.001)$ and preterm birth $(4.8 \%$ vs. $7.1 \%, p<0.001)$ were significantly lower. Women who subsequently developed GDM and PE had significantly higher $\mathrm{Hb}$ level in the first trimester than

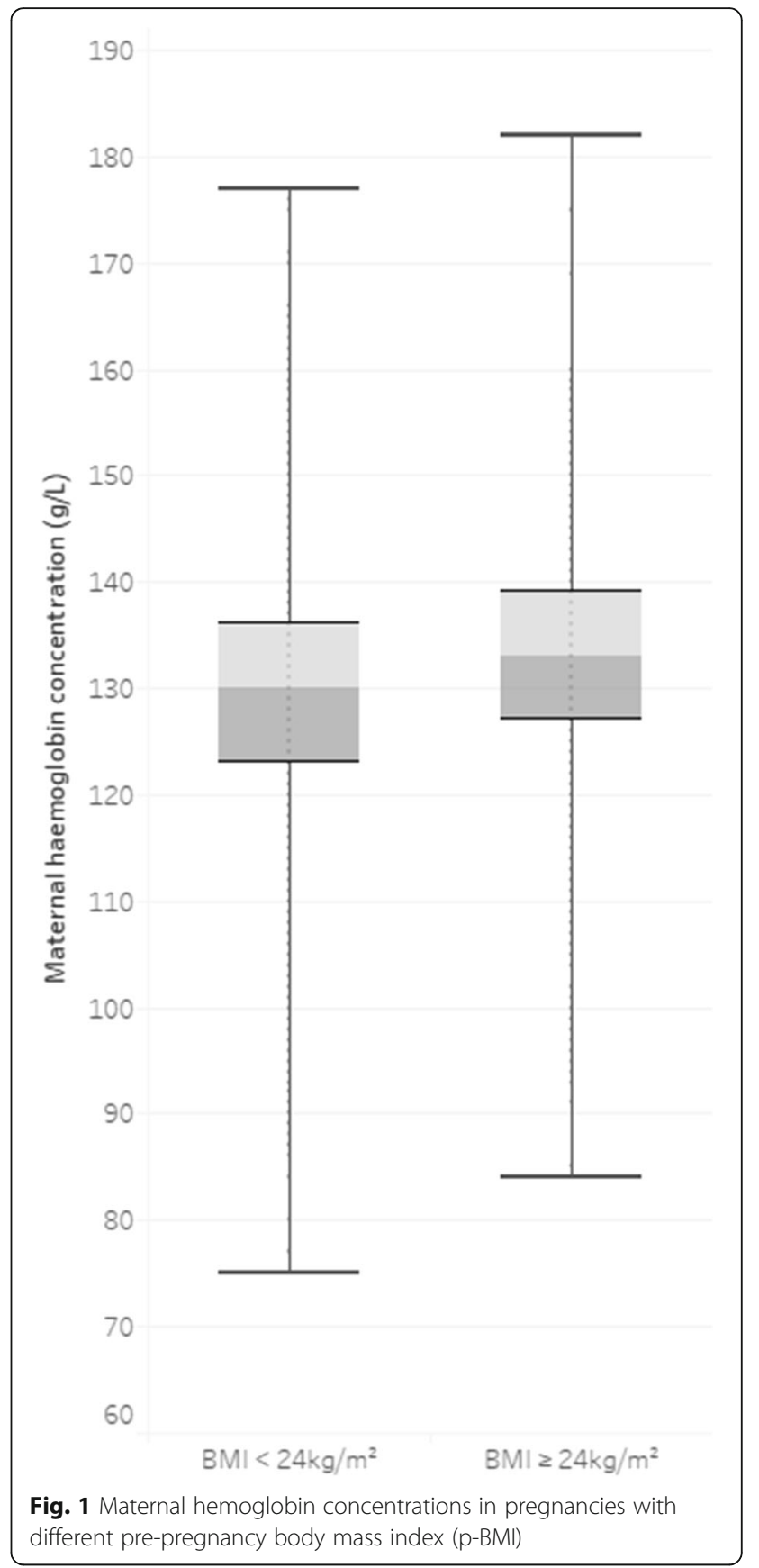

control subjects, whereas women with preterm deliveries had significantly lower $\mathrm{Hb}$ level in the first trimester. However, in women whose pre-pregnancy BMI was $<24 \mathrm{~kg} / \mathrm{m}^{2}$, the $\mathrm{Hb}$ levels were not significantly different between those who subsequently developed PE and those who did not. Furthermore, in women with a pre-pregnancy BMI $\geq 24 \mathrm{~kg} / \mathrm{m}^{2}$, the $\mathrm{Hb}$ levels of those with or without preterm birth were not significantly different (Table 2).

The multivariate logistic regression showed that the $\mathrm{Hb}$ levels during the first trimester were significantly 

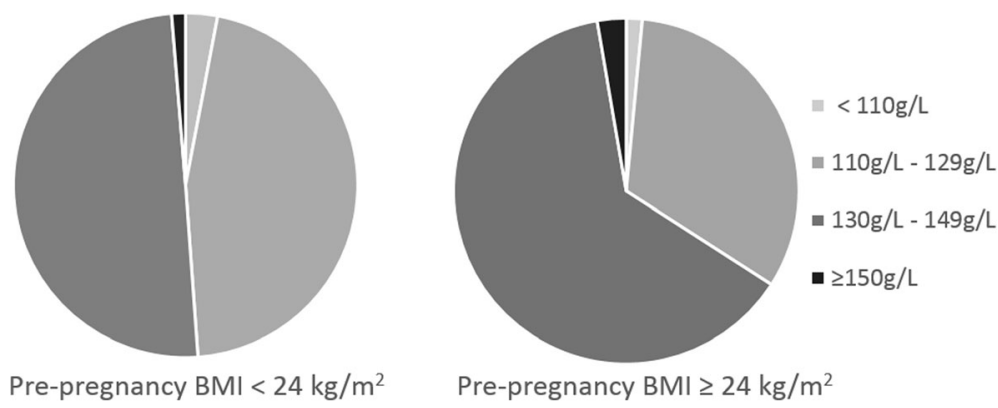

Fig. 2 The proportion of hemoglobin concentrations in women with different pre-pregnancy body mass index (p-BMI) categories

and positively associated with the risk of GDM and PE, which were significantly and negatively associated with the risk of preterm birth, even after adjusting for confounders. Overall, the adjusted ORs of GDM and PE increased, and the adjusted ORs of preterm birth decreased across increasing categories of $\mathrm{Hb}$ (P-trend for GDM: < 0.001; P-trend for PE: 0.001; P-trend for preterm birth: 0.001). After adjusting for confounders, the ORs comparing the high ranges with the reference range of $\mathrm{Hb}$ both demonstrated significantly increased odds of GDM (OR: 1.27 for $130 \mathrm{~g} / \mathrm{L} \leq \mathrm{Hb}<150 \mathrm{~g} / \mathrm{L} ;$ OR: 2.06 for $\mathrm{Hb} \geq 150 \mathrm{~g} / \mathrm{L}$ ) and PE (OR: 1.30 for $130 \mathrm{~g} / \mathrm{L} \leq \mathrm{Hb}<150 \mathrm{~g} / \mathrm{L}$; OR: 2.38 for $\mathrm{Hb} \geq 150 \mathrm{~g} / \mathrm{L}$ ). In addition, the ORs of preterm birth (OR: 0.80 for $130 \mathrm{~g} / \mathrm{L} \leq \mathrm{Hb}<150 \mathrm{~g} / \mathrm{L}$; OR: 0.38 for $\mathrm{Hb} \geq 150 \mathrm{~g} / \mathrm{L}$ ) were significantly lower for the high ranges than that for the reference range of $\mathrm{Hb}$. Furthermore, a 1.4-fold increased odds of preterm birth was observed when comparing the anemia group with the reference group (see Table 3 and Fig. 3).th=tlb=

The associations between the $\mathrm{Hb}$ level in the first trimester and GDM persisted in the subgroups as defined by the pre-pregnancy BMI. However, the associations between $\mathrm{Hb}$ and $\mathrm{PE}$ and the associations between $\mathrm{Hb}$ and preterm birth were null among the women whose pre-pregnancy BMI was $<24 \mathrm{~kg} / \mathrm{m}^{2}$ and the women whose pre-pregnancy was $\mathrm{BMI} \geq 24 \mathrm{~kg} / \mathrm{m}^{2}$, respectively. In particular, after adjusting for confounders, $\mathrm{Hb}$ levels greater than $130 \mathrm{~g} / \mathrm{L}$ in the first trimester significantly increased the GDM risk (OR: 1.274 for $130 \mathrm{~g} / \mathrm{L} \leq \mathrm{Hb}<150 \mathrm{~g} / \mathrm{L}$; OR: 1.844 for $\mathrm{Hb} \geq 150 \mathrm{~g} / \mathrm{L}$ ), whereas a significantly decreased risk of preterm birth was observed in the women whose pre-pregnancy BMI was $<24 \mathrm{~kg} / \mathrm{m}^{2}$ (OR: 0.768 for $130 \mathrm{~g} / \mathrm{L} \leq \mathrm{Hb}<150 \mathrm{~g} / \mathrm{L}$; OR: 0.233 for $\mathrm{Hb} \geq 150 \mathrm{~g} / \mathrm{L}$ ). Furthermore, the ORs of GDM and preterm birth increased and decreased across increasing ranges of $\mathrm{Hb}$, respectively. When the $\mathrm{Hb}$ levels surpassed $150 \mathrm{~g} / \mathrm{L}$, the risk of PE in women whose pre-pregnancy BMI was $<24 \mathrm{~kg} / \mathrm{m}^{2}$ also rose significantly (OR: 2.535 for $\mathrm{Hb} \geq 150 \mathrm{~g} / \mathrm{L}$ ). However, for women whose pre-pregnancy BMI was $\geq 24 \mathrm{~kg} / \mathrm{m}^{2}$, only $\mathrm{Hb}$ levels higher than $150 \mathrm{~g} / \mathrm{L}$ were associated with a higher risk of developing GDM (OR: 2.333 for $\mathrm{Hb} \geq 150 \mathrm{~g} / \mathrm{L})$. The associations between $\mathrm{Hb} \geq 150 \mathrm{~g} / \mathrm{L}$ and PE risk were attenuated and became non-significant after adjusting for confounders (Table 3, Fig. 3). Additionally, the continuous association between $\mathrm{Hb}$ levels in the first trimester and the risks of GDM, PE and preterm birth in the total population and the BMI subgroups can be seen in Fig. 4.

\section{Discussion}

In this large study of pregnant women, we found that women whose pre-pregnancy BMI was $\geq 24 \mathrm{~kg} / \mathrm{m}^{2}$ had significantly higher levels of $\mathrm{Hb}$ in the first trimester than women whose pre-pregnancy BMI was $<24 \mathrm{~kg} / \mathrm{m}^{2}$. Furthermore, women who subsequently developed GDM and PE had significantly higher $\mathrm{Hb}$ levels during the first trimester than controls, whereas women with preterm birth had significantly lower $\mathrm{Hb}$ levels in the first trimester. After adjusting for potential confounders, $\mathrm{Hb}$ levels during the first trimester were significantly and positively associated with the risk of GDM and PE and were significantly and negatively associated with the risk of preterm birth. Moreover, among the women whose pre-pregnancy BMI was $<24 \mathrm{~kg} / \mathrm{m}^{2}$, Hb levels greater than $130 \mathrm{~g} / \mathrm{L}$ during the first trimester were associated with a significantly higher GDM risk and lower rates of preterm birth. Furthermore, when the Hb levels exceeded $150 \mathrm{~g} / \mathrm{L}$, the risk of PE was significantly elevated. However, among the women whose pre-pregnancy BMI was $\geq 24 \mathrm{~kg} / \mathrm{m}^{2}$, only $\mathrm{Hb}$ levels higher than $150 \mathrm{~g} / \mathrm{L}$ increased the risk of GDM.

Similar to our results, an earlier observational study of 730 Chinese pregnant women revealed that high maternal $\mathrm{Hb}$ levels $(>130 \mathrm{~g} / \mathrm{L})$ in the first trimester were associated with a significantly higher incidence of GDM [16]. As early as 1986, Murphy et al. [17] conducted a study on 44,316 pregnant women and found that women with high $\mathrm{Hb}$ levels before 24 weeks of gestation had significantly higher rates of $\mathrm{PE}$. A recently retrospective cohort study of 920 singleton pregnancies indicated that pregnant women with $\mathrm{Hb}$ values $\geq 125 \mathrm{~g} / \mathrm{L}$ before 14 


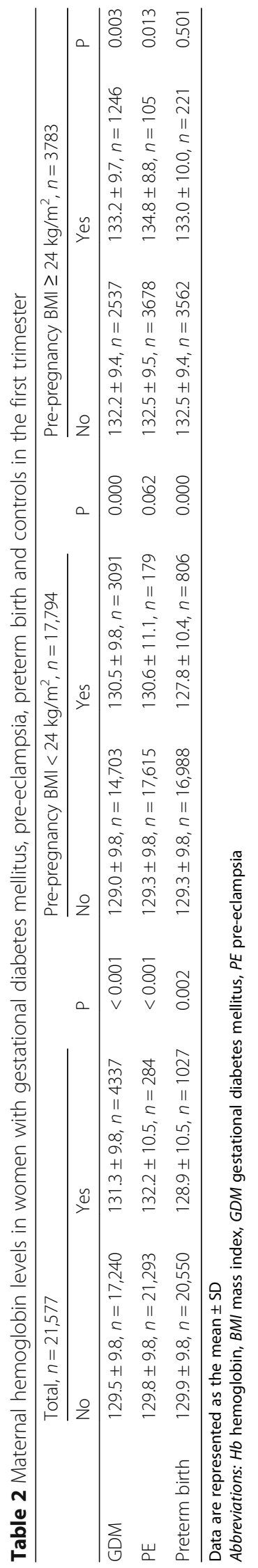




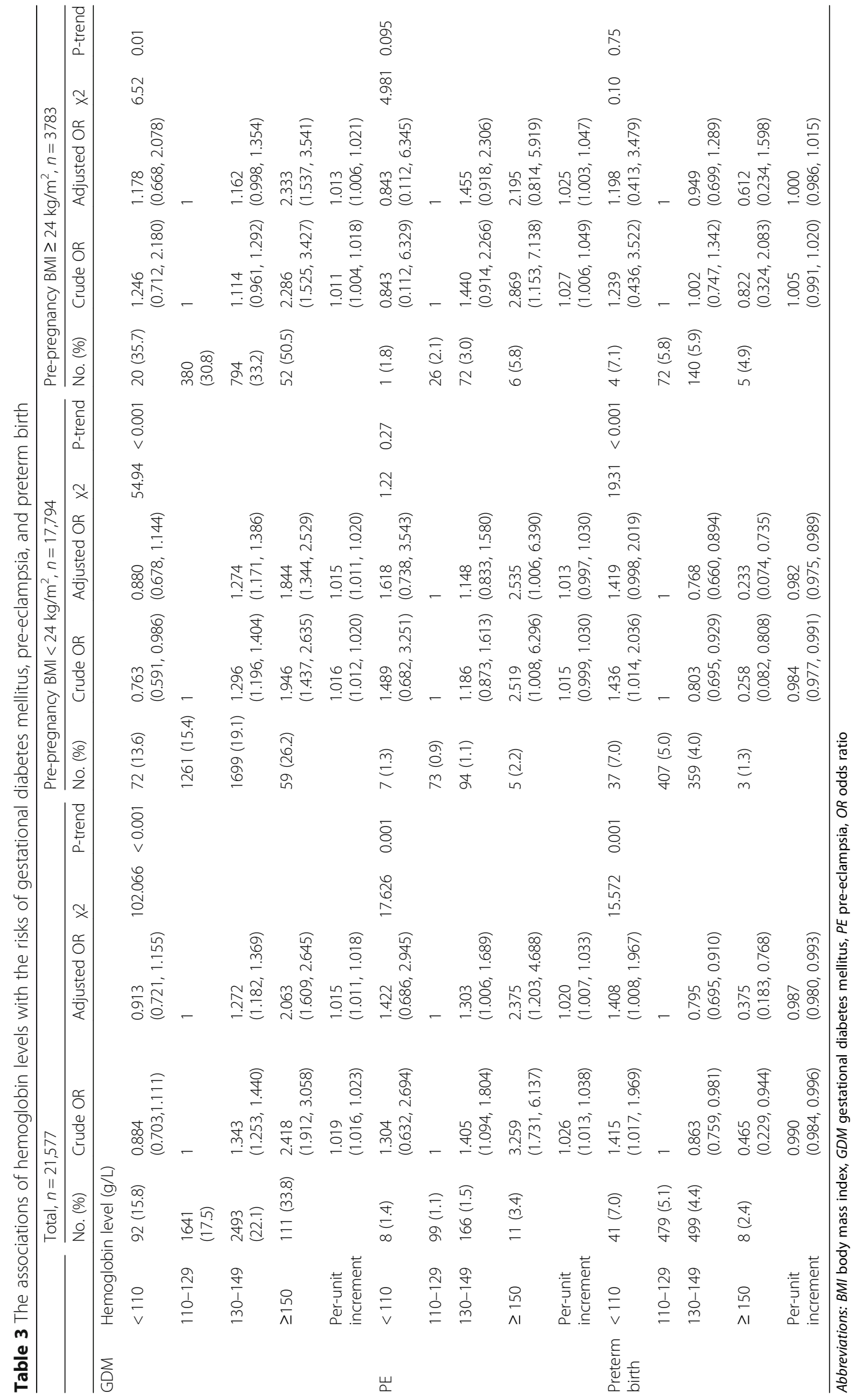




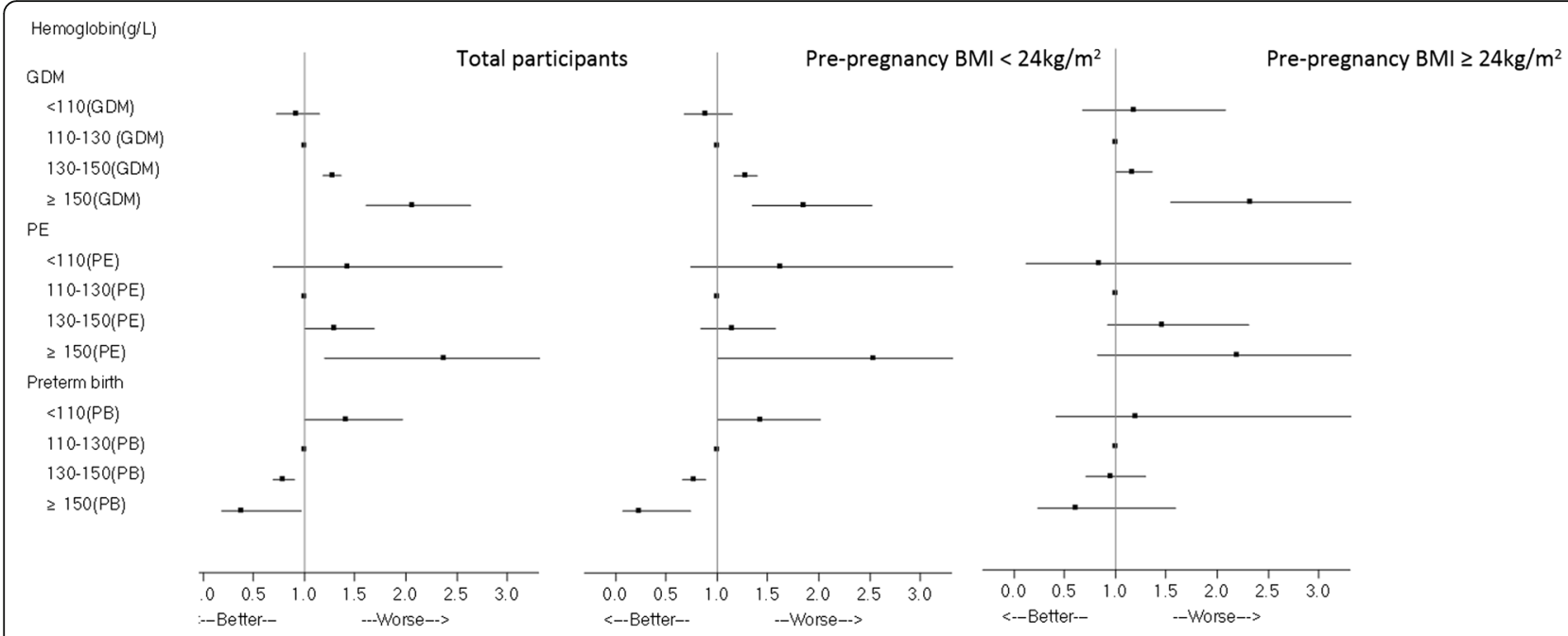

Fig. 3 Effects of hemoglobin concentration on GDM, PE and preterm birth during the first trimester

gestational weeks had a 3.8- and 3.3-fold increased risk of developing PE and GDM, respectively, compared with women with $\mathrm{Hb}$ values of $110-124 \mathrm{~g} / \mathrm{L}$ [10]. Similarly, in the report by Mehrabian and Hosseini [18] on 973 pregnancies during 2011-2012, significantly higher incidences of GDM and PE were found among women who had early pregnancy $\mathrm{Hb}$ values $\geq 125 \mathrm{~g} / \mathrm{L}$ than those with $\mathrm{Hb}$ values $<125 \mathrm{~g} / \mathrm{L}$. The $\mathrm{OR}$ values of the relative risks were 3.7 (95\% CI; 2.2 to 6.4 ) and 5.4 (95\% CI; 2.8 to 10.5 ), respectively [18]. Our findings are generally in line with those from these studies. Pregnant women in our study with $\mathrm{Hb}$ levels $\geq 130 \mathrm{~g} / \mathrm{L}$ had an increased risk of GDM and $\mathrm{PE}$, and the association became more significant when the $\mathrm{Hb}$ levelss exceeded $150 \mathrm{~g} / \mathrm{L}$.

The association observed in this and other studies between $\mathrm{Hb}$ levels and the risk of GDM and PE seems biologically plausible. Notably, the results presented in both our study and others $[12,16]$ showed that women with high $\mathrm{Hb}$ levels had higher pre-pregnancy BMI, which suggested that the high $\mathrm{Hb}$ levels may be a consequence of their better nutritional status. Furthermore, the high nutritional status may be related to an elevated risk of GDM and PE. Additionally, we hypothesized that high $\mathrm{Hb}$ levels may reflect iron overload because iron supplementation in high doses has been confirmed to have a role in the occurrence of GDM [19]. Accumulating evidence has demonstrated that iron is a strong prooxidant, and iron overload can increase $\beta$-cell oxidative stress, thus causing insulin resistance and impaired glucose metabolism [20].

The mechanism underlying the contribution of $\mathrm{Hb}$ to PE may primarily involve high blood viscosity. Hyperviscosity can directly reduce blood flow in the low kinetic force microvasculature, such as the placenta [21]. This may lead to reduced perfusion and oxygenation of placental tissue, therefore exacerbating placental tissue hypoxia as a direct result of low-velocity placental circulation and reduced oxygen supply. Moreover, $\mathrm{Hb}$ has a direct role in nitric oxide $(\mathrm{NO})$ regulation and endothelial function. NO is a potent vasodilator and can relax vascular smooth muscle cells. Free $\mathrm{Hb}$ can bind and inactive $\mathrm{NO}$, thus leading to vasoconstriction with consequent hypertension [22] and placental ischemia. Furthermore, oxidized $\mathrm{Hb}$ could create methemoglobinderived heme deposits on the vascular endothelium, which in turn directly damage the endothelium or promote atheroma formation via the effect of oxidized low-density lipoproteins [23].

In addition to GDM and PE, our study revealed a significant association between anemia and a high risk of preterm birth. Furthermore, the risk of preterm birth decreased with increasing $\mathrm{Hb}$ levels in the first trimester, particularly among women whose pre-pregnancy BMI was $<24 \mathrm{~kg} / \mathrm{m}^{2}$. Other studies have also confirmed that anemia is an independent risk factor for preterm birth, although studies on $\mathrm{Hb}$ levels and the risk of preterm birth are sparse. A retrospective study comparing singleton pregnancies with and without anemia during the first trimester in woman who delivered between 1988 and 2002 showed that compared with non-anemic women, higher rates of preterm birth $(<37$ weeks gestation) were found among women with anemia $(10.7 \% \mathrm{vs}$. $9.0 \%$, respectively, $p<0.001$ ). Moreover, maternal anemia was an independent risk factor for preterm birth even after adjusting for confounders $(\mathrm{OR}=1.2$; 95\% CI 1.1-1.2, $p<0.001$ ) [24]. At a different period of $\mathrm{Hb}$ measurement, an analysis of 295,651 pregnant women found that high preterm rates were observed with $\mathrm{Hb}$ levels $<110 \mathrm{~g} / \mathrm{L}$, and the relative risk increased across decreasing ranges of $\mathrm{Hb}$. Furthermore, women with $\mathrm{Hb}$ levels higher than $145 \mathrm{~g} / \mathrm{L}$ 


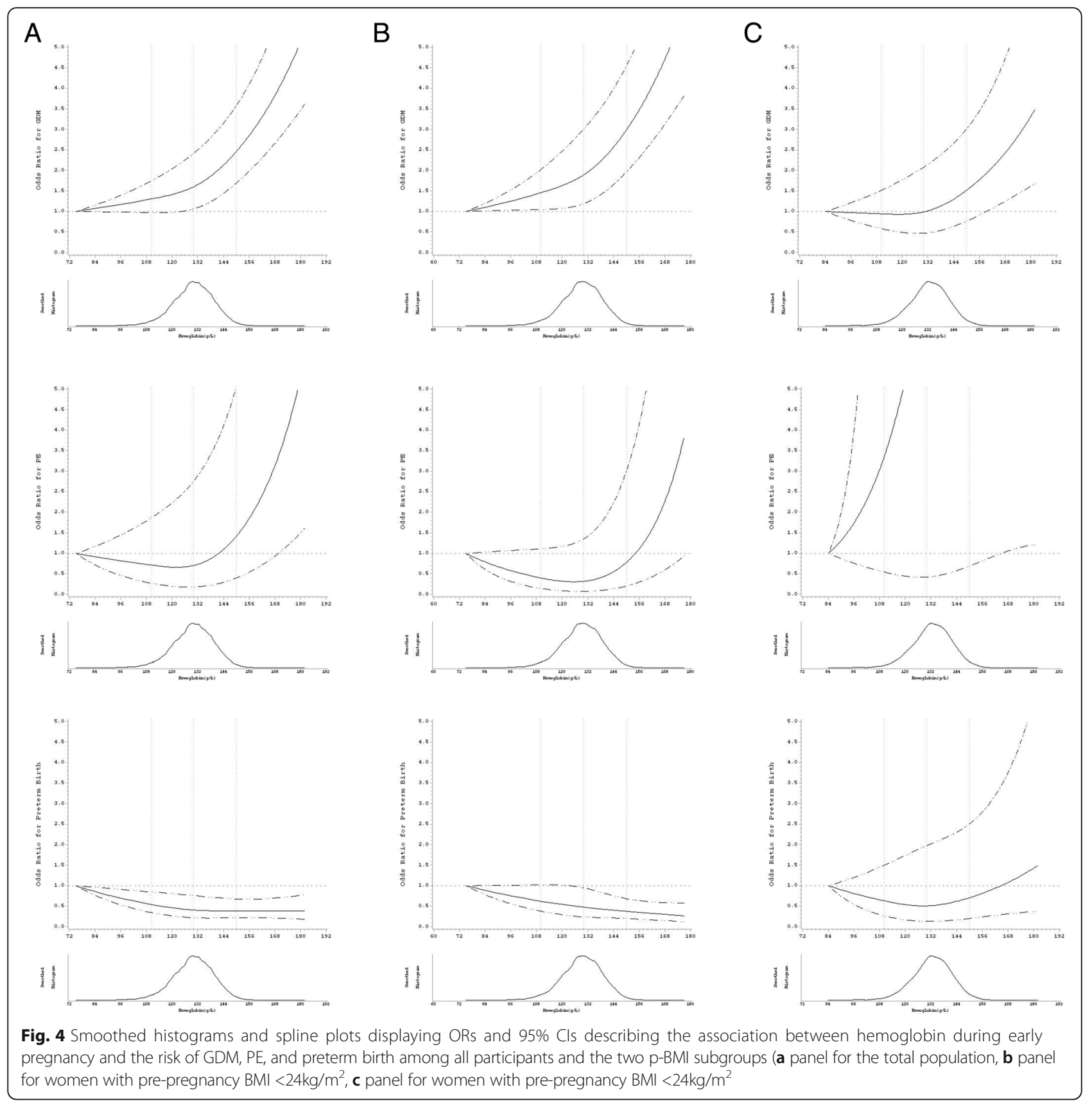

were also associated with a significantly increased risk of preterm birth (OR: 1.14; 95\% CI 1.05, 1.25) [25]. In contrast to the above findings, women with $\mathrm{Hb}$ levels $>130 \mathrm{~g} / \mathrm{L}$ in our study had a significantly decreased risk of preterm birth, and the relative risk decreased across increasing ranges of $\mathrm{Hb}$. However, an international multicenter cross-sectional study of 5690 singleton and nulliparous pregnancies indicated that there was no statistically significant effect of anemia on the risk of preterm birth [26]. In our opinion, variations in population characteristics of the studied participants in the different studies may be the main reason explaining these inconsistent results.

Additionally, several studies have confirmed that irondeficiency anemia, rather than anemia from other causes, influences preterm birth [27, 28]. Thus, they postulated that iron deficiency may be the cause of preterm birth. However, to date, the exact mechanisms underlying iron deficiency or iron-deficiency anemia and preterm birth have not yet been established. The possible 
mechanism may involve inadequate transfer of oxygen to the uterus, placenta, and fetus due to a damaged $\mathrm{Hb}$ transport capacity caused by iron deficiency.

After we conducted subgroup analyses stratified by pre-pregnancy BMI, we found that the associations of increased $\mathrm{Hb}$ with the risk of developing GDM remained in each subgroup. Although a trend towards increasing incidence of PE with elevated $\mathrm{Hb}$ levels was only noted in women whose pre-pregnancy BMI was $\geq 24 \mathrm{~kg} / \mathrm{m}^{2}$, the protective effects of high $\mathrm{Hb}$ levels on preterm birth were seen only in the women whose pre-pregnancy BMI was $<24 \mathrm{~kg} / \mathrm{m}^{2}$. These results seem to suggest that $\mathrm{Hb}$ levels in the first trimester play varied roles on the occurrence of PE and preterm birth in different prepregnancy BMI categories. In addition, $\mathrm{Hb}$ levels in the first trimester were significantly higher in the women whose pre-pregnancy BMI was $\geq 24 \mathrm{~kg} / \mathrm{m}^{2}$ compared to the women whose pre-pregnancy BMI was $<24 \mathrm{~kg} / \mathrm{m}^{2}$, and their estimated risk $\mathrm{Hb}$ level values in the first trimester were $150 \mathrm{~g} / \mathrm{L}$ and $130 \mathrm{~g} / \mathrm{L}$, respectively. Thus, these findings imply that pre-pregnancy BMI should be considered when evaluating $\mathrm{Hb}$ levels in the first trimester. However, to date, there are no uniform standards defining a high $\mathrm{Hb}$ level.

Our study was a multicenter study and the first to perform a joint analysis of maternal pre-pregnancy BMI and $\mathrm{Hb}$ on the occurrence of GDM, PE and preterm birth. The sample size in our study is very large. Additionally, our study was conducted by trained staff, and most of the data were collected from medical records, which ensured the standardization of data collection. Furthermore, the subgroup analyses stratified by prepregnancy BMI allowed us to show that pre-pregnancy BMI plays a role on influencing the associations between $\mathrm{Hb}$ levels and pregnancy outcomes. However, our study is retrospective, and the recruited pregnant women were from three cities in China. In addition, there are some differences between the original cohort and the final study cohort. Thus, these limitations could introduce bias and limit the generalization of the study findings to all pregnant women in China. Additionally, it should be noted that the sample size of our study may still be insufficient in some of the subgroups, such as the group of women whose $\mathrm{Hb}$ levels were $<110 \mathrm{~g} / \mathrm{L}$ and prepregnancy BMI was $\geq 24 \mathrm{~kg} / \mathrm{m}^{2}$, which may partially explain the non-significant results. Additionally, the number of participants with $\mathrm{PE}$ and preterm birth may also be deficient in our study to evaluate a statistically significant difference due to our exclusion criteria. Recent studies have noted that elevated iron stores may play a role in the development of GDM during pregnancy $[19,29]$. However, we do not have data regarding either maternal iron levels or ferritin levels in this study, and we also do not have data regarding supplements taking such as folic acid or iron tablets in the first trimester. Therefore, we could not determine whether the observed anemia was related to iron deficiency, nor make a detailed discussion on the impact of supplements on anemia, nor even perform a joint analysis of $\mathrm{Hb}$ levels and iron status in the present study. Furthermore, depending on the results of our study and others, establishing a balance between iron status and $\mathrm{Hb}$ levels may be a future challenge and should be revealed through more rigorously designed studies.

\section{Conclusions}

The data shown in our study confirmed that $\mathrm{Hb}$ levels during the first trimester play a role in predicting the risk of GDM, PE, and preterm birth. These findings are of clinical and public health importance, since they help clinicians be aware of these complications early in pregnancy other than these syndromes appear overt signs or symptoms later. Thus improving pregnancy outcomes through early intervention to the greatest extent.

\section{Abbreviations}

BMI: Body mass index; Cl: Confidence interval; GDM: gestational diabetes mellitus; Hb: Hemoglobin; OGTT: Oral glucose tolerance test; OR: Odds ratio; PE: Pre-eclampsia

\section{Acknowledgments}

We acknowledge all financial support of the study, and we thank all the obstetricians, nurses and students in our research group for their participation in the data collection.

\section{Availability of the data and materials \\ The datasets used and/or analyzed during the current study are available from the corresponding author on reasonable request.}

\section{Funding}

This study was supported by: "China GDM centers-Establishment and Training Dissemination" from the World Diabetes Foundation (Grant number WDF10-517), "Sample library construction and plasma biomarker investigation on recurrent spontaneous abortion and preeclampsia" from the Major Program of the National Natural Science Foundation of China (81490745) and the 973 National Science and Technology Plan Project (2015CB94330). These funding bodies accepted the study as proposed and played roles in the design of the study, the collection, analysis, and interpretation of data or writing the manuscript.

\section{Authors' contributions \\ CW participated in the collection and analysis of the data and drafted the manuscript. CW and HY contributed substantially to the initial study conception and design. JY, LL, WZ, YW, RS, HF, BL and SL monitored data collection and revised the paper. All authors read and approved the final manuscript.}

\section{Ethics approval and consent to participate}

This study was reviewed and approved by the Institutional Review Board of the First Hospital, Peking University (Reference number: 2013[578]). All participants provided written informed consent, and the Ethics Committee approved the consent procedure.

Competing interests

The authors declare that they have no competing interests.

\section{Publisher's Note}

Springer Nature remains neutral with regard to jurisdictional claims in published maps and institutional affiliations. 


\section{Author details}

'Department of Obstetrics and Gynecology of Peking University First Hospital, Xianmen Street No. 1, Xicheng District, Beijing 100034, China. ${ }^{2}$ National Institute of Hospital Administration, Beijing, China.

\section{Received: 2 March 2017 Accepted: 30 April 2018}

Published online: 26 June 2018

\section{References}

1. Vogel JP, Souza JP, Mori R, Morisaki N, Lumbiganon P, Laopaiboon M, et al. Maternal complications and perinatal mortality: findings of the World Health Organization multicountry survey on maternal and newborn health. BJOG. 2014;121(Suppl 1):76-88. https://doi.org/10.1111/1471-0528.12633.

2. Hod M, Kapur A, Sacks DA, Hadar E, Agarwal M, Di Renzo GC, et al. The International Federation of Gynecology and Obstetrics (FIGO) initiative on gestational diabetes mellitus: a pragmatic guide for diagnosis, management, and care. Int J Gynaecol Obstet. 2015;131(Suppl 3):S173-211. https://doi.org/ 10.1016/S0020-7292(15)30007-2.

3. Umesawa M, Kobashi G. Epidemiology of hypertensive disorders in pregnancy: prevalence, risk factors, predictors and prognosis. Hypertens Res. 2016; https://doi.org/10.1038/hr.2016.126.

4. Sacks DA, Hadden DR, Maresh M, Deerochanawong C, Dyer AR, Metzger BE, et al. Frequency of gestational diabetes mellitus at collaborating centers based on IADPSG consensus panel-recommended criteria: the hyperglycemia and adverse pregnancy outcome (HAPO) study. Diabetes Care. 2012;35:526-8. https://doi.org/10.2337/dc11-1641.

5. Blencowe $H$, Cousens $S$, Oestergaard MZ, Chou D, Moller AB, Narwal R, et al. National, regional, and worldwide estimates of preterm birth rates in the year 2010 with time trends since 1990 for selected countries: a systematic analysis and implications. Lancet. 2012;379:2162-72. https://doi.org/10.1016/ S0140-6736(12)60820-4

6. Rogers LK, Velten M. Maternal inflammation, growth retardation, and preterm birth: insights into adult cardiovascular disease. Life Sci. 2011;89: 417-21. https://doi.org/10.1016/j.lfs.2011.07.017.

7. Nutritional anaemias. Report of a WHO group of experts. WHO Tech Rep Ser. 1972:503:1-29.

8. Annamraju H, Pavord S. Anaemia in pregnancy. Br J Hosp Med. 2016;77: 584-8. https://doi.org/10.12968/hmed.2016.77.10.584.

9. Huisman A, Aarnoudse JG. Increased 2nd trimester hemoglobin concentration in pregnancies later complicated by hypertension and growth retardation. Early evidence of a reduced plasma volume. Acta Obstet Gynecol Scand. 1986; 65:605-8. https://doi.org/10.3109/00016348609158396.

10. Phaloprakarn C, Tangjitgamol S. Impact of high maternal hemoglobin at first antenatal visit on pregnancy outcomes: a cohort study. J Perinat Med. 2008:36:115-9. https://doi.org/10.1515/JPM.2008.018.

11. Tarim E, Kilicdag E, Bagis T, Ergin T. High maternal hemoglobin and ferritin values as risk factors for gestational diabetes. Int J Gynaecol Obstet. 2004;84: 259-61. https://doi.org/10.1016/S0020-7292(03)00341-2.

12. Rasmussen S, Bergsjø P, Jacobsen G, Haram K, Bakketeig LS. Haemoglobin and serum ferritin in pregnancy-correlation with smoking and body mass index. Eur J Obstet Gynecol Reprod Biol. 2005;123:27-34. https://doi.org/10. 1016/j.ejogrb.2005.02.012.

13. Zhou B. Coorperative meta-analysis group of China obesity task force [Predictive values of body mass index and waist circumference to risk factors of related diseases in Chinese adult population]. Zhonghua Liu Xing Bing Xue Za Zhi. 2002;23:5-10.

14. Diagnostic criteria and classification of hyperglycaemia first detected in pregnancy. A World Health Organization guideline. Diabetes Res Clin Pract. 2014;103:341-63. https://doi.org/10.1016/j.diabres.2013.10.012.

15. WHO. WHO: recommended definitions, terminology and format for statistical tables related to the perinatal period and use of a new certificate for cause of perinatal deaths. Modifications recommended by FIGO as amended October 14, 1976. Acta Obstet Gynecol Scand. 1977;56:247-53.

16. Lao TT, Chan LY, Tam KF, Ho LF. Maternal hemoglobin and risk of gestational diabetes mellitus in Chinese women. Obstet Gynecol. 2002:99:807-12.

17. Murphy JF, O'Riordan J, Newcombe RG, Coles EC, Pearson JF. Relation of haemoglobin levels in first and second trimesters to outcome of pregnancy. Lancet. 1986;1:992-5. https://doi.org/10.1016/S0140-6736(86)91269-9.
18. Mehrabian F, Hosseini SM. Comparison of gestational diabetes mellitus and pre-eclampsia in women with high hemoglobin in the first trimester of pregnancy: a longitudinal study. Pak J Med Sci. 2013;29:986-90. https://doi.org/10.12669/pjms.294.4012.

19. Bowers K, Yeung E, Williams MA, Qi L, Tobias DK, Hu FB, et al. A prospective study of prepregnancy dietary iron intake and risk for gestational diabetes mellitus. Diabetes Care. 2011;34:1557-63. https://doi.org/10.2337/dc11-0134.

20. Liu Q, Sun L, Tan Y, Wang G, Lin X, Cai L. Role of iron deficiency and overload in the pathogenesis of diabetes and diabetic complications. Curr Med Chem. 2009;16:113-29. https://doi.org/10.2174/092986709787002862.

21. Cho Yl, Cho DJ. Hemorheology and microvascular disorders. Korean Circ J. 2011;41:287-95. https://doi.org/10.4070/kcj.2011.41.6.287.

22. Treuer AV, Gonzalez DR. Nitric oxide synthases, S-nitrosylation and cardiovascular health: from molecular mechanisms to therapeutic opportunities (review). Mol Med Rep. 2015:11:1555-65. https://doi.org/10.3892/mmr.2014.2968.

23. Tsemakhovich VA, Bamm W, Shaklai M, Shaklai N. Vascular damage by unstable hemoglobins: the role of heme-depleted globin. Arch Biochem Biophys. 2005;436:307-15. https://doi.org/10.1016/j.abb.2005.02.006.

24. Levy A, Fraser D, Katz M, Mazor M, Sheiner E. Maternal anemia during pregnancy is an independent risk factor for low birthweight and preterm delivery. Eur J Obstet Gynecol Reprod Biol. 2005;122:182-6. https://doi.org/ 10.1016/j.ejogrb.2005.02.015

25. Gonzales GF, Tapia V, Gasco M, Carrillo CE. Maternal hemoglobin concentration and adverse pregnancy outcomes at low and moderate altitudes in Peru. J Matern Fetal Neonatal Med. 2012;25:1105-10. https://doi.org/10.3109/14767058.2011.623200.

26. Masukume G, Khashan AS, Kenny LC, Baker PN, Nelson G, SCOPE Consortium. Risk factors and birth outcomes of anaemia in early pregnancy in a nulliparous cohort. PLoS One. 2015;10:e0122729. https://doi.org/10.1371/journal.pone.0122729.

27. Lu ZM, Goldenberg RL, Cliver SP, Cutter G, Blankson M. The relationship between maternal hematocrit and pregnancy outcome. Obstet Gynecol. 1991;77:190-4. https://doi.org/10.1097/00006250-199102000-00005.

28. Scholl TO, Hediger ML, Fischer RL, Shearer JW. Anemia vs iron deficiency: increased risk of preterm delivery in a prospective study. Am J Clin Nutr. 1992;55:985-8.

29. Rawal S, Hinkle SN, Bao W, Zhu Y, Grewal J, Albert PS, et al. A longitudinal study of iron status during pregnancy and the risk of gestational diabetes: findings from a prospective, multiracial cohort. Diabetologia. 2017;60:249-57. https://doi.org/10.1007/s00125-016-4149-3.

\section{Ready to submit your research? Choose BMC and benefit from:}

- fast, convenient online submission

- thorough peer review by experienced researchers in your field

- rapid publication on acceptance

- support for research data, including large and complex data types

- gold Open Access which fosters wider collaboration and increased citations

- maximum visibility for your research: over $100 \mathrm{M}$ website views per year

At BMC, research is always in progress.

Learn more biomedcentral.com/submissions 